Revista Brasileira de Agricultura Irrigada v.13, nº.6, p. 3765 - 3772, 2019

ISSN 1982-7679 (On-line)

Fortaleza, CE, INOVAGRI - http://www.inovagri.org.br

DOI: $10.7127 /$ rbai.v13n6001161

Protocolo 1161.19 - 04/05/2020 Aprovado em 11/05/2020

\title{
CULTIVO ADENSADO DE ORA-PRO-NÓBIS IRRIGADO NO TERRITÓRIO DO SISAL BAIANO
}

Clayton Moura de Carvalho ${ }^{1}$, Ires Silva da Luz $^{2}$, Delfran Batista dos Santos ${ }^{3}$, Delka de Oliveira Azevedo $^{4}$, Raimundo Rodrigues Gomes Filho ${ }^{5}$, Manoel Valnir Júnior ${ }^{6}$

\begin{abstract}
RESUMO
Aliada a escassez hídrica na região semiárida vem a falta de fontes proteicas de alimentação humana e animal no período de estiagem aumentando assim o custo de produção dos mesmos, sendo assim a ora-pro-nóbis (Pereskia aculeata) uma planta da família das Cactáceas, surge como alternativa por apresentar altos teores de proteína e ferro. Sendo assim, o objetivo da pesquisa foi analisar o comportamento do cultivo adensado da ora-pro-nóbis influenciado pela irrigação com volume fixo no território do sisal baiano. $\mathrm{O}$ trabalho foi conduzido em área experimental instalada no Instituto Federal Baiano, Campus Serrinha, em uma área de $120 \mathrm{~m}^{2}$ com população inicial de 80 plantas com fileiras duplas de plantas espaçadas de 2,0 x 1,0 x 1,0 m e irrigadas com volume fixo de 2 litros de água semanal através do sistema de irrigação localizada por gotejamento. Foram avaliadas variáveis relacionadas ao percentual de pegamento de mudas em diferentes classes de diâmetro das hastes e à produção de fitomassa fresca da planta (folhas, hastes e total). A classe de diâmetro das hastes compreendida entre 6 e 15,99 $\mathrm{mm}$ apresenta grande potencial para a propagação vegetativa de orapro-nóbis no território do Sisal baiano. A produtividade média de matéria fresca de folhas por planta foi estimada em aproximadamente $10 \mathrm{t}$ de folhas ha ${ }^{-1}$.
\end{abstract}

Palavras-chave: Pereskia aculeata, semiárido, irrigação localizada.

\section{DENSE CULTIVATION ORA-PRO-NÓBIS OF IRRIGATED IN THE TERRITORY OF SISAL BAIANO}

\begin{abstract}
Allied to water scarcity in the semi-arid region is the lack of protein sources for human and animal food in the dry season, thus increasing the cost of producing them, thus the ora-pro-nobis (Pereskia aculeata) a plant of the Cactaceae family, it appears as an alternative for presenting high levels of

\footnotetext{
${ }^{1}$ Doutor em Eng. Agrícola, Professor do IF Baiano Campus Serrinha, e-mail: clayton.carvalho@ifbaiano.edu.br

2 Técnica em Agropecuária, IF Baiano Campus Serrinha, e-mail:iressilva50@gmail.com

${ }^{3}$ Doutor em Eng. Agrícola, Professor do IF Baiano Campus Serrinha, e-mail: delfran.santos@ifbaiano.edu.br

${ }^{4}$ Doutora em Eng. Agrícola, Professora do IF Baiano Campus Serrinha, e-mail: delka.azevedo@ifbaiano.edu.br

${ }^{5}$ Doutor em Eng. Agrícola, Professor da UFS, e-mail: rrgomesfilho@ hotmail.com

${ }^{6}$ Doutor em Eng. Agrícola, Professor do IFCE Campus Sobral, e-mail: valnir jvm@yahoo.com.br
} 
protein and iron. Thus, the objective of the research was to analyze the behavior of the densified cultivation of ora-pro-nobis influenced by irrigation with fixed volume in the territory of the Bahian sisal. The work was carried out in an experimental area installed at the Federal Institute of Bahia, Campus Serrinha, in an area of $120 \mathrm{~m}^{2}$ with an initial population of 80 plants with double rows of plants spaced $2.0 \times 1.0 \times 1.0 \mathrm{~m}$ and irrigated with volume fixed 2 liters of water weekly through the drip irrigation system. Variables related to the percentage of seedling taking up in different classes of stem diameter and the production of fresh plant phytomass (leaves, stems and total) were evaluated. The stem diameter class between 6 and $15.99 \mathrm{~mm}$ has great potential for the vegetative propagation of ora-pro-nobis in the territory of Bahia's Sisal. The average fresh matter yield of leaves per plant was estimated at approximately $10 \mathrm{t}$ of leaves ha- ${ }^{-1}$.

Keywords: Pereskia aculeata, semiarid, localized irrigation.

\section{INTRODUÇÃO}

A água é fundamental para que haja vida, entretanto, várias partes do mundo sofrem com uma crise hídrica decorrente, principalmente, da má utilização desse recurso, pela distribuição das precipitações e aumento da demanda pelo crescimento populacional e aliada a escassez hídrica vem a falta de fontes proteicas de alimentação humana e animal no período de estiagem aumentando assim o custo de produção dos mesmos.

A ora-pro-nóbis surge como uma alternativa para o cultivo no semiárido nordestino, visto que é uma espécie pertencente à subfamília Pereskioideae, considerada detentora do maior número de caracteres primitivos da família Cactaceae (BARBOSA, 2012). A planta é resistente à seca, própria de clima tropical e subtropical, encontrada em domínios brasileiros de Caatinga, Cerrado e Mata Atlântica. Devido a sua rusticidade, a planta adapta-se aos diversos tipos de solo, não sendo exigente em fertilidade (BRASIL, 2010; PAULUCIO et al., 2014).

Segundo Zappi et al. (2010) essa espécie no Nordeste brasileiro, predomina nos Estados do Maranhão, Pernambuco, Bahia, Alagoas e Sergipe; no Centro Oeste pode ser encontrada em Góias; no Sudeste é comumente utilizada na culinária de Minas Gerais, Espírito Santo, São Paulo e Rio de Janeiro e no Sul, é encontrada no Paraná e em Santa Catarina.

Por seu elevado valor proteico, pode atingir, nas folhas, $25 \%$ de proteína, das quais
85\% acham-se na forma digestível, ela precisa ser melhor aproveitada na alimentação humana e animal. E, ainda como planta medicinal, visto que já é utilizada no abrandamento de processos inflamatórios e na recuperação da pele em caso de queimadura. Já seus frutos são expectorantes e antissifilíticos (ANDRADE, 2012; ARAÚJO; JOAQUIM, 2007).

Segundo Paulucio et al. (2014) como a ora-pro-nóbis apresenta alto valor proteico, pode ser utilizada como complementação alimentar na alimentação animal, possuindo também grande quantidade de ferro, sendo utilizada como fonte de ferro e proteína bruta.

Por todas essas características a planta em questão pode tornar-se uma interessante alternativa de atividade agrícola, sendo cultivada irrigada com volume fixo para obtenção de matéria verde como fonte de proteína e ferro para suprir a alimentação humana e/ou animal no território do sisal baiano. O objetivo da pesquisa foi analisar o comportamento do cultivo adensado da orapro-nóbis influenciado pela irrigação com volume fixo no território do sisal baiano

\section{MATERIAL E MÉTODOS}

O experimento foi implantado na Unidade Educativa de Campo do Grupo de Estudos e Pesquisa Agropecuária na Caatinga - GEPAC no Instituto Federal Baiano, Campus Serrinha, situado no município de Serrinha no Estado da Bahia (Figura 1), cujo as coordenadas geográficas do município são 
$11^{\circ} 37^{\prime} 28^{\prime \prime} \mathrm{S}, 38^{\circ} 58^{\prime} 26^{\prime \prime} \mathrm{W}$ e 359 metros de altitude. Segundo a classificação de Köppen, o município apresenta classificação climática Aw clima tropical com chuvas de verão, sendo a temperatura média de $23,5^{\circ} \mathrm{C}$ e pluviosidade média anual de $801 \mathrm{~mm}$. O solo caracteriza-se como um Latossolo Vermelho-Amarelo distrófico, típico A fraco, textura média, fase Caatinga hipoxerófila, relevo plano a suave ondulado.

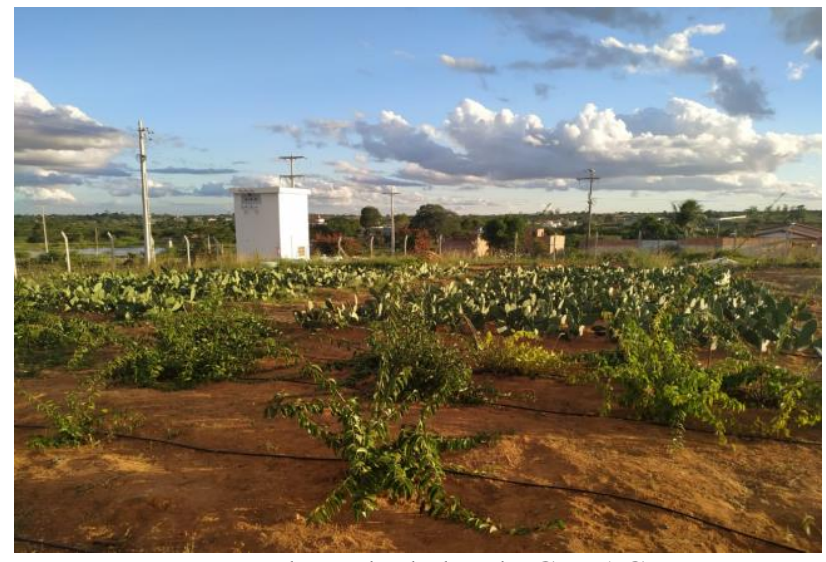

Fonte: base de dados do GEPAC

Figura 1. Área experimental do cultivo de ora-pro-nóbis

A área total do experimento cultivada com a ora-pro-nóbis (Pereskia aculeata Mill.) é de $120 \mathrm{~m}^{2}(6 \mathrm{~m} \times 20 \mathrm{~m})$, o plantio foi realizado com fileiras duplas de plantas espaçadas de $2,0 \times 1,0 \times 1,0 \mathrm{~m}$, gerando uma densidade total de 80 (oitenta) plantas na área experimental. As estacas (hastes) de ora-pronóbis foram obtidas de plantas adultas com aproximadamente 10 (dez) anos de idade originaria do município de Janaúba localizada no norte do estado de Minas Gerais. O solo que foi utilizado para encher os sacos de produção das mudas foi caracterizado como um Latossolo Vermelho-Amarelo distrófico típico A fraco (EMBRAPA, 2018), textura média preparado a partir da mistura de $50 \%$ de solo e $50 \%$ de esterco bovino curtido.
Para a confecção das mudas, as estacas foram cortadas com auxílio de um alicate de poda com comprimento de $30 \mathrm{~cm}$ cada com diâmetro variando de 3 a $15,99 \mathrm{~mm}$. As estacas foram enterradas $2 / 3$ no solo e as regas eram realizadas diariamente (Figura 2 ).

Com o auxílio de um paquímetro digital realizou-se a mensuração do diâmetro da haste para posterior relação com a formação das mudas.

O pegamento das hastes (formação das mudas) foi avaliado aos 21 dias após o plantio onde foram consideradas mudas mortas as que não possuíam respectivamente folhas nem raízes. As mudas foram organizadas em função de quatro classes de diâmetros, sendo: $2<6 ; 6<11$ e $11 \leq 16 \mathrm{~mm}$.

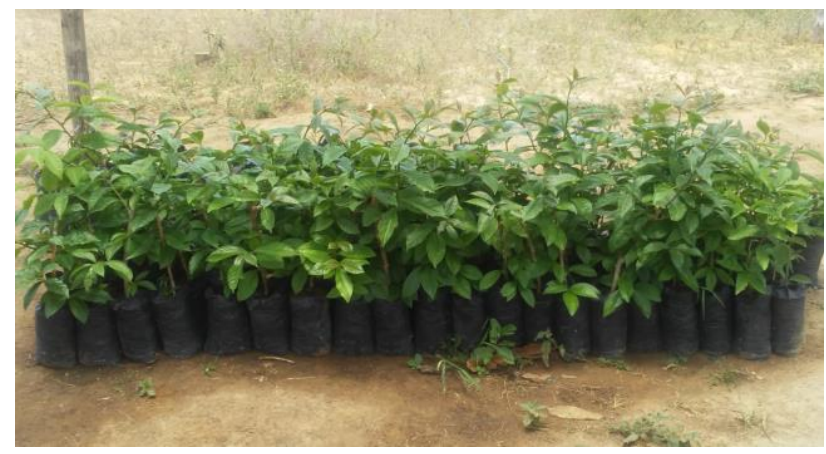

Fonte: Base de dados do GEPAC

Figura 2. Mudas de ora-pro-nóbis 30 dias após o plantio das estacas 
Na etapa de transplantio as mudas foram levadas para área definitiva da Unidade Educativa de Campo do Grupo de Estudos e Pesquisa Agropecuária na Caatinga - GEPAC no Instituto Federal Baiano, Campus Serrinha. O preparo do solo da área foi realizado com uso de trator agrícola, obedecendo espaçamento de plantio de 1,0 metro entre plantas e 2,0 metros entre linhas duplas de plantio e 0,3 metros de profundidade do sulco de plantio.

Nos sulcos de plantio foram aplicados esterco bovino curtido com proporções equivalentes a 10 toneladas de adubo orgânico por hectare. Após o plantio e adubação foram realizadas regas semanais com volume fixo equivalentes a 2 litros de água por planta aplicadas através de sistema de irrigação localizada por gotejamento. Foram realizadas 2 capinas durante os 8 meses de observação da cultura em campo; a primeira com 2 meses após o transplantio e a segunda com 6 meses após o transplantio.

As observações do ataque de pragas e incidência de doenças foram realizadas semanalmente e registradas em diário de campo e através de fotografias in loco.

O sistema foi avaliado pelo método de Keller e Karmeli (1975) no início do experimento e após o período de 1 (um) ano, cauculando-se o Coeficiente de Uniformidade de Distribuição - CUD nos períodos distintos. Foram avaliadas neste experimento as variáveis relacionadas ao pegamento das mudas em relação ao diâmetro das hastes e à fitomassa fresca (folhas e hastes) em virtude ao período de climatização na área experimental.

$\mathrm{Na}$ etapa de avalição da produção fitomassa fresca (matéria verde das folhas e hastes) as plantas foram submetidas a poda drástica para fins de pesagem das folhas e hastes. A poda foi realizada oito (8) meses após o transplantio com o auxílio de um alicate de poda para a corte dos ramos, as folhas por sua vez foram retiradas manualmente para posterior pesagem da matéria fresca de folhas e hastes em balança de precisão no laboratório de ciências agrárias do IF Baiano Campus Serrinha.

\section{RESULTADOS E DISCUSSÃO}

De acordo com os resultados obtidos, observa-se na Tabela 1 que o maior percentual de pegamento das estacas de ora-pro-nóbis foi obtido nas hastes que apresentaram diâmetros variando entre 11 e $15,99 \mathrm{~mm}$. E que o menor percentual de pegamento foi obtido naquelas hastes com diâmetros variando de 2 a 5,99 $\mathrm{mm}$.

Tabela 1. Percentual de pegamento das estacas de ora-pro-nóbis em função das classes de diâmetros das hastes.

\begin{tabular}{cc}
\hline Diâmetro $(\mathrm{mm})$ & Pegamento $(\%)$ \\
\hline $2<6$ & 57 \\
$6<11$ & 79 \\
$11 \leq 16$ & 100 \\
\hline
\end{tabular}

Este melhor resultado para a classe de maior diâmetro de hastes (11 a 15,99 mm) foi, possivelmente, devido à maior quantidade de reservas pré-existentes nestas estacas, onde correu maior crescimento e desenvolvimento destas. Ressalta-se que os carboidratos de reserva servem como fonte de energia e produção de esqueletos carbônicos necessários para a produção de novos tecidos (MARCHESE et al., 2010). A baixa quantidade de reservas, como por exemplo, carboidratos, não fornecerá a energia necessária para que ocorra bom enraizamento das estacas (VEIERSKOV, 1988; MAYER et 
al., 2006), pois a capacidade de uma estaca emitir raízes é função da interação de fatores endógenos e das condições ambientais proporcionadas ao enraizamento (NICOLOSO et al., 2001). Resultados similares, foram encontrados por Marchese et al. (2010) e Biase e Costa (2003) em estudo com plantas de Lippia alba (Mill.). Após o transplantio e estabelecimento da cultura em campo, observou-se que as plantas começaram a apresentar lesões foliares, provavelmente associadas a incidência de alguma praga e/ou doença; e folhas amareladas e murchas sem razão aparente (Figura 3).

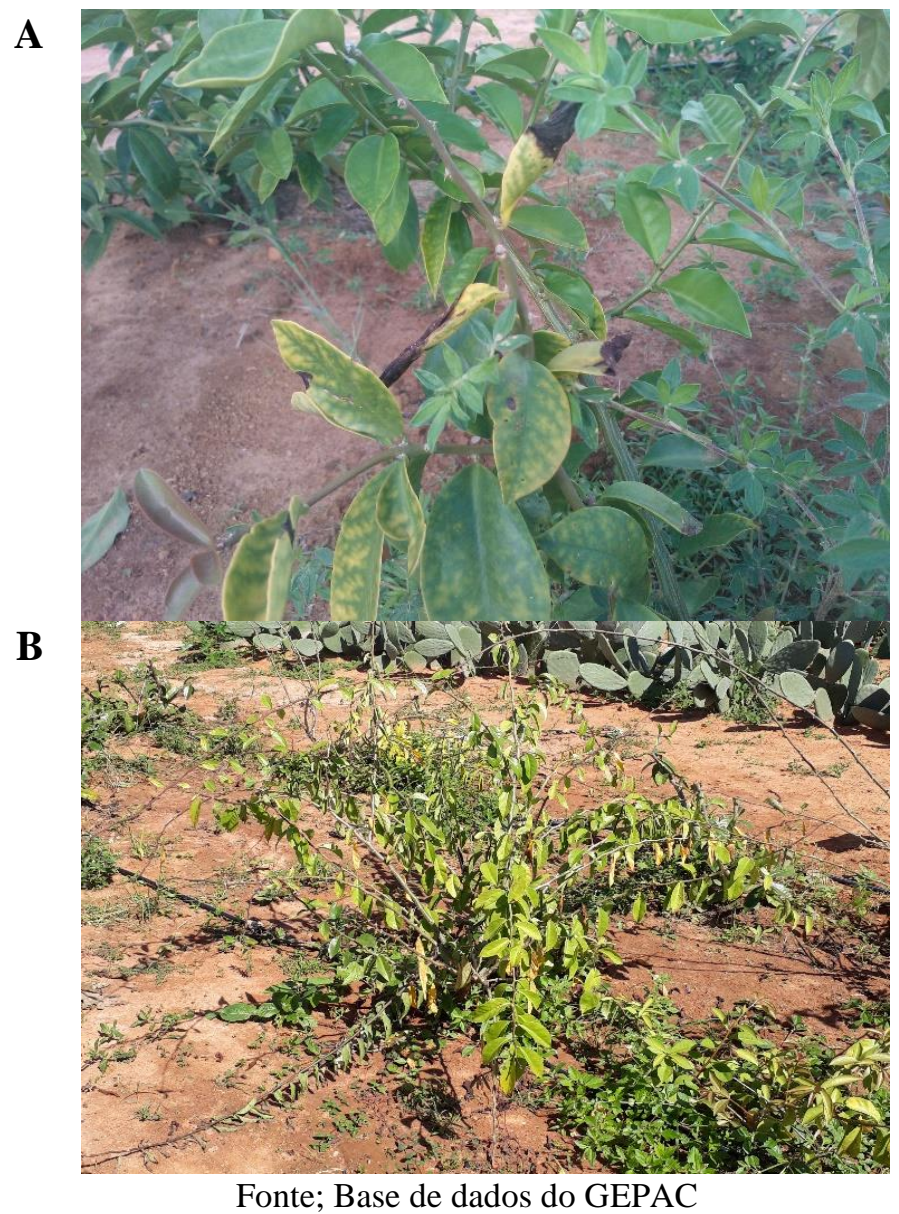

Figura 3. (A e B) Plantas de ora-pro-nóbis apresentando sintomas não identificados

Verificou-se que plantas apresentando coloração verde intensa e bem vigorosas, com ramos e folhas bem desenvolvidas, por vezes sem ataque aparente de pragas e/ou doenças, estavam morrendo sem razões aparentes. Esse resultado diz respeito a capacidade de enraizamento; visto que a parte área conseguiu se desenvolver de forma exitosa, porém a raiz que tem como principais funções servir como meio de fixação da planta ao solo e como órgão absorvente de água e nutrientes como se encontrava pouco desenvolvida não conseguiu atender as necessidades da planta na velocidade necessária, o que, consequentemente, pode ter acarretado a morte gradativa da planta.

Seguindo com as observações, foi constatado também que o sistema radicular, já estava em processo de decomposição. Uma amostra desse material (raiz, caule e folha) foi encaminhado para o Laboratório de Fitopatologia da UNIVASF onde foi descartada a hipótese de ataque e/ou contaminação por patógeno.

Na Figura 4A e 4B estão apresentados o percentual de mortalidade das plantas realizado aos 4 (quatro) e 6 (seis) meses após o transplantio, respectivamente. 
A
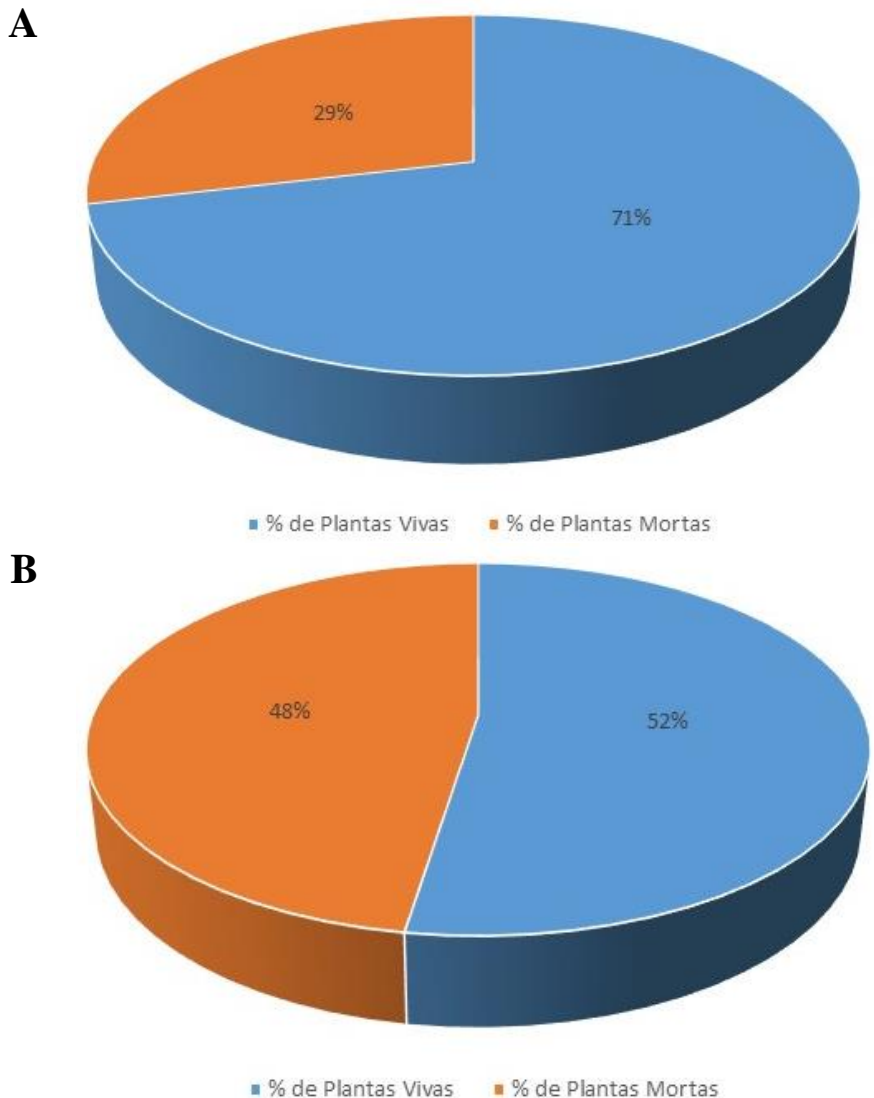

Figura 4. Percentual de mortalidade de plantas de ora-pro-nóbis com 4 meses (A) e 8 meses (B) após o transplantio

Observa-se na Figura 4A que do total de 80 plantas transplantadas na área, 23 plantas morreram em função de possíveis causas ainda desconhecidas representando um total de $29 \%$, e que após 2 meses este percentual subiu para 48\% (38 plantas mortas) conforme pode ser observado na Figura 4B. Essas causas possíveis podem ser observadas na Figura 2, onde estão apresentadas imagens de plantas com sintomas desconhecidos. Observou-se assim, num período de 2 meses, um aumento de mortalidade de plantas de 29 para $48 \%$, ou seja, partindo de 23 plantas mortas na área experimental para um total de 38. Após os seis meses de implantação aparentemente não houve mais indícios de novas plantas mortas na área de estudo.
Em estudos de taxa de sobrevivência de ora-pro-nóbis propagada por estaquia no Distrito Federal, Barros et al. (2015), identificaram uma taxa de mortalidade de $56 \%$ e atribuiu a estrutura radicular incipiente da planta propagada por estaquia. Essa mesma observação pode ser atribuída a este estudo no município de Serrinha - BA onde as plantas também foram propagadas por estaquia e não apresentaram um desenvolvimento radicular expressivo. Para confirmação desta causa fazse necessário maiores investigações acerca das causas do grande índice de mortandade das plantas. No que se refere a produção de matéria fresca das plantas da área experimental, os dados encontram-se representados na Tabela 2.

Tabela 2. Quantitativo médio de matéria fresca de ora-pro-nóbis.

\begin{tabular}{cc}
\hline Matéria Fresca (média por planta) & Massa $(\mathrm{g})$ \\
\hline Folhas & $1.509,51$ \\
Hastes & $1.053,06$ \\
Total & $2.562,57$ \\
\hline
\end{tabular}


Analisando a produção média de matéria fresca de folhas por planta de ora-pro-nóbis contidas na Tabela 2 , pode-se estimar uma produtividade de aproximadamente $10 \mathrm{t}$ de folhas $\mathrm{ha}^{-1}$, visto que cada planta ocupava uma área de $1,5 \mathrm{~m}^{2}$. Tal produção é bem superior a citada por Brasil (2010), onde afirma que a sua produtividade é estimada entre 2,5 a $5,0 \mathrm{t}$ de folhas ha- ${ }^{-1}$. Já Souza (2013) estudando a produção de folhas de ora-pro-nóbis com diferentes densidades de plantio encontrou a produção de 5,78 $\mathrm{t}$ de folhas ha $\mathrm{a}^{-1}$ com 1 planta por $\mathrm{m}^{2}$. Este resultado de elevada produtividade pode ser justificado por colheita única aos 8 meses de idade após o transplantio das plantas de ora-pro-nóbis para área definitiva.

Ao se fazer uma análise dos componentes da massa de matéria fresca total observou-se que a massa fresca das folhas é responsável por $59 \%$ do total de matéria fresca (Figura 5).

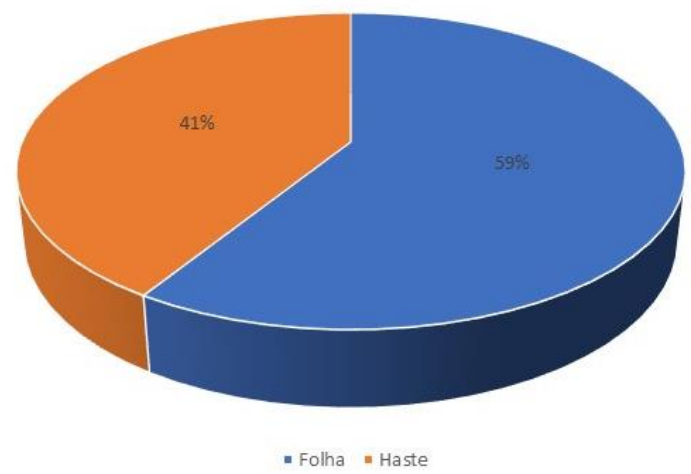

Figura 5. Componentes do total de matéria fresca total das plantas de ora-pro-nóbis.

\section{CONCLUSÕES}

A classe de diâmetro das hastes compreendida entre 6 e 15,99 mm apresenta grande potencial para a propagação vegetativa de ora-pro-nóbis no território do Sisal baiano.

Mesmo com o alto teor de mortalidade de plantas no período de adaptação na área de estudo, a ora-pro-nóbis com aplicação de volume semanal de água fixo de $2 \mathrm{~L}$ por planta apresentou produção média de matéria fresca de folhas elevado, caracterizando como uma alternativa viável para produção de proteína vegetal na região.

\section{AGRADECIMENTOS}

Os autores agradecem ao $\mathrm{CNPq}$ pela concessão da bolsa PIBIC Ensino Médio do segundo autor, ao IFBaiano pelo apoio financeiro, ao IFBaiano Campus Serrinha e ao Grupo de Estudos e Pesquisa Agropecuária na
Caatinga - GEPAC por todo apoio prestado do desenvolvimento da pesquisa

\section{REFERÊNCIAS BIBLIOGRÁFICAS}

ANDRADE, R. R. de. Substrato e irrigação em ora-pro-nóbis (Pereskia aculeata Mill.). 2012. 90p. Tese (Doutorado em agronomia). UNESP. Jaboticabal, 2012.

ARAÚJO, T. V.; JOAQUIM, W. M. Análise da germinação de sementes de ora-pro-nobis (Pereskia aculeata) in vitro. In: X Encontro Latino Americano De Iniciação Científica e VI Encontro Latino Americano de Pósgraduação. Anais... UNIVAP, 2007.

BARBOSA, C. K. R.; FINGER, F. L.; CASALI, V. W. D.; OLIVEIRA, L. S. PEREIRA, D. M. Manejo e conservação póscolheita de Pereskia aculeata Mill. em temperatura ambiente. Horticultura 
Brasileira, v. 30, n. 2 (suplemento), p. s7002s7009, 2012.

BARROS, B. K.; GOMES, W. B.; LUZARDO, J. R.; SILVA, J. L. A.; BARBOSA, J. B. M.; MORAIS, I. T.; PAIS, N. O.; FALEIRO, F. G.; ALONSO, A. M.; AQUINO, F. G.; ALBUQUERQUE, L. B. Taxa de sobrevivência de espécies de maracujá e ora-pro-nobis em experimento de restauração ecológica de mata ripária do Distrito Federal. In: $2^{\circ}$ Simpósio sobre Processos Ecológicos, Restauração e Ecovaloração de Zonas Ripárias, 2015, Brasília. Taxa de sobrevivência de espécies de maracujá e ora-pro-nobis em experimento de restauração ecológica de mata ripária do Distrito Federal, 2015.

BIASI, L. A.; COSTA, G. Propagação vegetativa de Lippia alba. Ciência Rural, v.33, n.3, p.455-9, 2003.

BRASIL. Manual de hortaliças não convencionais. Brasília: Ministério da Agricultura Pecuária e Abastecimento Secretaria de Desenvolvimento Agropecuário e Cooperativismo, Brasília: MAPA/ACS, 2010, 94p.

EMPRESA BRASILEIRA DE PESQUISA AGROPECUÁRIA - EMBRAPA. Sistema brasileiro de classificação de solos. 5.ed. revisada e ampliada, Brasília-DF: Embrapa, 2018. 356p.

KELLER, J.; KARMELI, D. Trickle irrigation design. Rain Bird Sprinkler Manufacturing Corporation, 1975. 133 p.

MARCHESE, J. A.; PISSAIA, E.; BOCCHESE, V. C. C.; CAMBRUZZI, E.; COLUSSI, G.; HART, V.; MAGIERO, E. C. Estacas de diferentes diâmetros na propagação de Lippia alba (Mill.) N.E.Br. - Verbenaceae.
Revista brasileira de plantas medicinais, v.12, n.4, p.506-509, 2010. http://dx.doi.org/10.1590/S151605722010000400015.

MAYER, J. L. S.; BIASI, L. A.; BONA, C. Capacidade de enraizamento de estacas de quatro cultivares de Vitis L. (Vitaceae) relacionada com os aspectos anatômicos. Acta Botanica Brasilica, v.20, n.3, p.563-8, 2006.

NICOLOSO, F. T.; CASSOL, L. F.; FORTUNATO, R. P. Comprimento da estaca de ramo no enraizamento de ginseng brasileiro (Pfaffia glomerata). Ciência Rural, v.31, n.1, p.57-60, 2001.

PAULUCIO, V. A. P.; BRUNORO, G. P.; ASSUNÇÃO, G. R.; CORDEIRO, M. D.; OLIVEIRA, L. R. S.; GAI, Z. T. Produção de sementes e mudas como fontes proteicas alternativas na alimentação animal: cartilha para produtores. CAUFES: Alegre-ES, 2014. $24 \mathrm{p}$.

SOUZA, M. R. M. Ora-pro-nobis (Pereskia aculeata Mill.) como alternativa promissora para produção de proteína: densidade de plantio e adubação nitrogenada. Tese (doutorado em Fitotecnica) - Universidade Federal de Viçosa. Viçosa - MG, 2013. 89 f.

VEIERSKOV, B. Relations between carbohydrates and adventitious root formation. In: DAVIS, T. D.; HAISSIG, B. E.; SANKHLA, N. Adventitious root formation in cuttings. Portland: Dioscorides, 1988. p.248-73.

ZAPPI, D., TAYLOR, N., MACHADO, M. Cactaceae in Lista de Espécies da Flora do Brasil. 2010. Jardim Botânico do Rio de Janeiro. Disponível em: <http://floradobrasil.jdrj.gov.br/2010/fb00163 >. Acesso em: 18 fev 2014. 